\title{
Modifiable Factors Associated with Reversion from Mild Cognitive Impairment to Cognitively Normal Status: A Prospective Cohort Study
}

\section{Feng Sha}

Shenzhen Institutes of Advanced Technology Chinese Academy of Sciences

\section{Ziyi Zhao}

Shenzhen Institutes of Advanced Technology Chinese Academy of Sciences

Chang Wei

Shenzhen Institutes of Advanced Technology Chinese Academy of Sciences

\section{Zhirong Yang}

Shenzhen Institutes of Advanced Technology Chinese Academy of Sciences

Bingyu Li ( $\sim$ bingyuli@szu.edu.cn )

Shenzhen University https://orcid.org/0000-0002-8516-958X

\section{Research}

Keywords: dementia prevention, dietary/lifestyle factors, cognitive health

Posted Date: October 22nd, 2021

DOI: https://doi.org/10.21203/rs.3.rs-970706/v1

License: (9) This work is licensed under a Creative Commons Attribution 4.0 International License. Read Full License 


\section{Abstract \\ Background}

Previous studies found that about $24 \%$ of the mild cognitive impairment $(\mathrm{MCl})$ patients reverse to cognitively normal (CN) status. However, it is unclear which modifiable factors are associated with this reversion.

\section{Method}

We conducted a prospective community-based cohort study based on 2002-2018 Chinese Longitudinal Health Longevity Survey (CLHLS). Of 35,474 older adults from 22 provinces in China in the 5 waves of CLHLS, 7,422 eligible participants with $\mathrm{MCl}$ were included. Multivariable Cox regression with least absolute shrinkage and selection operator (LASSO) penalty for variable selection was adopted to investigate the associations between reversion to $\mathrm{CN}$ and potential modifiable dietary/lifestyle, cardiometabolic, and psychological factors.

\section{Results}

Our analysis included 7,422 MCI participants [average age: 90.0 (SD 9.5) years]. Among these participants, 1,604 (21.6\%) reversed from $\mathrm{MCl}$ to $\mathrm{CN}$ with a mean (SD) follow-up of 2.9 (1.8) years. Several dietary/lifestyle factors, including daily consumption of fresh fruits (Hazard Ratio [HR]: 1.28, 95\% Cl: 1.15 to 1.42; $\mathrm{P}$ 囚.001), engagement in reading (HR: 1.24, 95\% Cl: 1.00 to 1.54; $\mathrm{P}=.047$ ), housework (HR: $1.21,95 \% \mathrm{Cl}: 1.08$ to $1.35 ; \mathrm{P}=.001$ ), and mah-jong or other card games (HR: $1.23,95 \% \mathrm{Cl}: 1.08$ to $1.39 ; \mathrm{P}$ $=.001)$, were positively associated with possibility of reversion. Cigarette smoking (HR: 0.92, 95\% Cl: 0.84 to $1.00 ; \mathrm{P}=.041$ ) and duration of alcohol drinking (HR: $0.97,95 \% \mathrm{Cl}: 0.94$ to $0.99 ; \mathrm{P}=.012$ ) were negatively associated with possibility of reversion. None of the modifiable cardiometabolic and psychological factors was found to be significantly associated with reversion to $\mathrm{CN}$. Difference was identified among different age and gender group.

\section{Conclusion}

This study identified several dietary/lifestyle factors associated with $\mathrm{MCl}$ reversion that may transfer into large-scale dementia prevention practices.

\section{Introduction}

Dementia is one of the major causes of mortality and disease burden in the world, with no effective medical treatment so far (1). Increasing significance has been attached to preventive interventions, especially among those who have developed mild cognitive impairment $(\mathrm{MCl})$. A recent meta-analysis of 
25 cohort studies reported that the overall reversion rate from $\mathrm{MCl}$ to $\mathrm{CN}$ was $24 \%$, with a substantial discrepancy between clinic-based $(14 \%)$ and community-based studies $(31 \%)(2,3)$. This discrepancy may indicate that community-dwelling individuals with no need to refer to memory clinics may have less severe symptoms and a better chance to recover from $\mathrm{MCl}$. Therefore, interventions and health policies targeting community-dwelling $\mathrm{MCl}$ population may effectively prevent dementia. To achieve this, identifying modifiable factors associated with $\mathrm{MCl}$ reversion that potentially transfers into large-scale preventive practices is of key importance.

Much evidence has accumulated regarding modifiable factors associated with cognitive decline and dementia. Low education, smoking, heavy alcohol consumption, and lack of physical activities may increase the incidence of dementia (4), while Mediterranean diet may lower the risk (5). In terms of psychological factors, depression (6) and lack of social support (7) are associated with higher incidence of dementia. However, it is still unknown if modification of these risk factors could help cognition recovery in $\mathrm{MCl}$ patients.

Previous studies have identified several institutional and life-long modifiable factors associated with reversion from $\mathrm{MCl}$ to $\mathrm{CN}$. Institutional factors increasing possibility of $\mathrm{MCl}$ reversion include younger age and no APOEe4 allele (8-10), and modifiable factors increasing possibility of $\mathrm{MCl}$ reversion include higher score on baseline cognitive functioning and functional activities, non-amnestic $\mathrm{MCl}(9,10)$, higher education level, no hypertension, and no stroke (8). Although some of these factors are modifiable through life cycle, most of them cannot be changed among $\mathrm{MCl}$ patients, providing limited practical implications for dementia prevention in this population. Large multi-domain trials such as FINGER (11), MAPT (12) and PreDIVA (13) focusing on different multidomain lifestyle interventions have provided mixed results regarding whether these interventions targeting at-risk individuals are effective (14), probably because it is unclear which specific modifiable factors can make a difference among high-risk population.

To provide further evidence on effective prevention, this study investigated the associations between reversion from $\mathrm{MCl}$ to $\mathrm{CN}$ and potential modifiable factors, including dietary/lifestyle, cardiometabolic, and psychological factors after adjustment for the institutional factors.

\section{Methods}

\subsection{Study population}

The study analyzed data derived from the Chinese Longitudinal Health Longevity Survey (CLHLS). The CLHLS is a population-based prospective cohort study investigating factors that influence older adults' health, longevity, and mortality. Six waves of data were collected through multi-stage cluster sampling in $2002,2005,2008,2011,2014$ and 2018. All centenarians were invited and interviewed in the 801 randomly selected cities or counties. Older adults aged 65-79, 80-89, and 90-99 years in the same cluster were also invited to be investigated to match with each centenarian by sex and age, so that the four age 
groups (65-79, 80-89, 90-99, 100 and above) were comparable. New participants were recruited in the follow-up surveys to maintain a stable sample size. A detailed description of study design and assessment of data quality has been published elsewhere (15). Of the 35,474 participants in the first 5 waves, 8,840 were screened to have $\mathrm{MCl}$. We further excluded 9 people aged below 65,40 with hospitaldiagnosed dementia, and 1,369 with only baseline data. In the end, 7,422 $\mathrm{MCl}$ participants were included and a detailed enrolment flowchart can be found in Figure 1.

\subsection{Cognitive Assessment}

The validated Chinese version of Mini-Mental State Examination (CMMSE) (16) was conducted by trained health practitioners. The MMSE was widely applied in epidemiological studies to measure the cognitive function of older adults for its simplicity (17). It mainly included five domains: orientation, registration, attention and calculation, recall, and language. $\mathrm{MCl}$ was defined as CMMSE score between 18 and 23 (18, 19), and the year of the first $\mathrm{MCl}$ diagnosis (2002-2014) was set as the baseline for each participant. All living $\mathrm{MCl}$ participants included in this study had at least one follow-up assessment (2005-2018), and reversion was defined as an $\mathrm{MCI}$ participant reaching 24 or above in the follow-up CMMSE test for the first time $(18,19)$. As a reliable change in MMSE should be at least two to four points, we added an additional restriction of MMSE change $\geq 4$ points to the definition of $\mathrm{MCl}$ reversion (20). Sensitivity analysis was also conducted for other thresholds $(\geq 2, \& \geq 3)$.

\subsection{Potentially Modifiable factors}

Several potential modifiable dietary/lifestyle, cardiometabolic and psychological factors were assessed at baseline. To generate practical implications, only factors that are still modifiable after $\mathrm{MCl}$ diagnosis were selected as exposure variables in this study, while certain lifelong modifiable variables that can no longer be changed in later age were excluded. For example, alcohol consumption and cigarette smoking were included as modifiable factors, while education, which can no longer be changed in later life, is regarded as an institutional factor.

\subsubsection{Dietary/lifestyle factors}

A simplified food frequency questionnaire (FFQ) is used to measure the dietary habits and patterns: the type of staple food (rice, wheat, corn vs others) and its intake in 50 grams, frequency of fresh fruits and vegetables intake (daily vs sometimes or never), frequency of meat, fish, eggs, legume, salt-preserved vegetable, sugar, tea, and garlic (almost daily vs sometimes or never). Lifestyle habits mainly included physical exercise, current alcohol consumption, current cigarette smoking (yes vs no), duration of alcohol consumption (years), duration of cigarette smoking (years), frequency of cigarette smoking (times/day) and leisure activities, including doing housework, having personal outdoor activities, doing garden work, reading newspaper or books, raising domestic animals, playing mah-jong or other card games, watching TV / listening to the radio, and participating social activities (almost daily vs occasionally or never).

\subsubsection{Cardiometabolic factors}


The following variables were used to measure cardiometabolic factors: body mass index $\left(\mathrm{BMI}, \mathrm{kg} / \mathrm{m}^{2}\right)$, systolic blood pressure $(\mathrm{Hg} \mathrm{mm})$, diastolic blood pressure $(\mathrm{Hg} \mathrm{mm})$, and heart rate (beats/min). BMI was calculated with measured weight and inferred height from measured knee height due to the lack of unified questions about measured height (21).

\subsubsection{Psychological factors}

The variables about personality were constructed by two self-rated variables about life satisfaction (satisfied vs unsatisfied) and loneliness (Ionely vs not lonely). For life satisfaction, "very good", "good", or "fine" were defined as "satisfied"; otherwise, it was defined as "unsatisfied". For loneliness, if subjects always or often felt lonely, they were defined as "Ionely"; otherwise, they were defined as "not lonely".

\subsection{Institutional Factors (Covariates)}

The socioeconomic information on age, gender (female vs. male), ethnic group (other minorities vs Han), current residence area (urban vs. rural), co-residence status (with household members vs alone or in an institute), current marital status (married vs. unmarried), years of education and occupation before 60 years (agriculture vs non-agriculture) were collected at participates' baseline interview. The disability of older adults was measured with self-reported visionary function (good vs poor), chewing ability (good vs poor), score of activities of daily living (ADL) and instrumental activities of daily living (IADL). The selfreported history of illness included diabetes, heart disease, cerebrovascular disease, bronchitis, emphysema, asthma, and pneumonia (BEPA), and pulmonary tuberculosis (TB) were also included.

\subsection{Statistical Analysis}

Multivariable cox regression with least absolute shrinkage and selection operator (LASSO) for variable selection was implemented to select variables and investigate their associations with reversion (22). By minimizing the residual sum of squares plus a shrinkage penalty of lambda multiplied by the sum of absolute values of the coefficients, the LASSO model performs variable selection in that it restricts some of the coefficients to be exactly zero. It has been found in simulation study that LASSO is more accurate and provides a more stable final model than the traditional variable selection methods, such as stepwise (23). We first generated hypotheses by using LASSO to select potential modifiable factors; the multivariable Cox proportional hazard regression was then applied to estimate their hazard ratio (HR) and $95 \%$ confidence interval. The proportional hazard assumption was tested with the Schoenfeld residuals. To reduce the potential bias from missing values, multiple imputation was implemented to acquire completed dataset with the method of random forest in MICE (24). We conducted several sensitive analyses to check the robustness of the main results: 1 ) using stepwise (back-n-forth) Cox regression model to select variables; 2$)$ applying an additional restriction of MMSE change ( $\geq 2, \& \geq 3)$ points) to our definition of reversion; 3 ) using listwise deletion to handle missing data; 4) using the modified Fine and Gray competing risks method to address the possibility that those who died could have developed dementia had they lived longer. Subgroup analyses by age groups (65-79, 80-89, 90-99 and 100+ years old) and sex were conducted. All statistical analysis was conducted using R 3.4.3 for Windows. 


\section{Results}

Of 7,422 MCl participants aged 90.0 years old on average, 2584 (34.8\%) were male, 6848 (92.3\%) were Han people, 2866 (38.6\%) were urban residents, 157 (2.1\%), 537 (7.2\%), $382(5.1 \%), 682$ (9.2\%) and 34 $(0.5 \%)$ reported a history of diabetes, heart disease, cerebrovascular disease, BEPA and TB, respectively. $1,604(21.6 \%)$ experienced reversion from $\mathrm{MCl}$ to $\mathrm{CN}$ with average follow-up of 2.86 years. A summary of the baseline characteristics of the reversed and non-reversed $\mathrm{MCl}$ participants can be found in Table 1 . 
Table 1

Baseline characteristics for the study participants.

\begin{tabular}{|c|c|c|c|c|}
\hline Variables & $\begin{array}{l}\text { Reversion } \\
(n=1604)\end{array}$ & $\begin{array}{l}\text { Non- } \\
\text { reversion } \\
(n=5818)\end{array}$ & $\begin{array}{l}\text { Total } \\
(\mathrm{n}=7422)\end{array}$ & $\begin{array}{l}\text { Missing } \\
\text { (\%) }\end{array}$ \\
\hline Follow-up Duration, mean (SD) & $3.4(1.8)$ & $2.7(1.9)$ & $2.9(1.8)$ & - \\
\hline \multicolumn{5}{|l|}{ Potential Covariates } \\
\hline Age (years), mean (SD) & $82.7(9.2)$ & $92.0(8.6)$ & $90.0(9.5)$ & - \\
\hline Sex, male $(\%)$ & $633(39.5)$ & $1951(33.5)$ & $\begin{array}{l}2584 \\
(34.8)\end{array}$ & - \\
\hline MMSE(points), mean (SD) & $21.0(1.7)$ & $20.8(1.7)$ & $20.9(1.7)$ & - \\
\hline Ethnic group, Han (\%) & $\begin{array}{l}1493 \\
(93.1)\end{array}$ & $5355(92.0)$ & $\begin{array}{l}6848 \\
(92.3)\end{array}$ & $79(1.1)$ \\
\hline Current residence area, Urban (\%) & $578(36.0)$ & $2288(39.3)$ & $\begin{array}{l}2866 \\
(38.6)\end{array}$ & - \\
\hline Living with household members (\%) & $\begin{array}{l}1238 \\
(77.2)\end{array}$ & $4643(79.8)$ & $\begin{array}{l}5881 \\
(79.2)\end{array}$ & $7(0.1)$ \\
\hline Education (years), mean (SD) & $1.4(2.7)$ & $1.0(2.4)$ & $1.1(2.5)$ & $48(0.6)$ \\
\hline Occupations, Non-agriculture (\%) & $396(26.4)$ & $1685(29.0)$ & $\begin{array}{l}2081 \\
(28.0)\end{array}$ & $\begin{array}{l}115 \\
(1.5)\end{array}$ \\
\hline Current marital status, Married (\%) & $594(37.0)$ & $1012(17.4)$ & $\begin{array}{l}1606 \\
(21.6)\end{array}$ & $10(0.1)$ \\
\hline Visionary function, Good (\%) & $\begin{array}{l}1363 \\
(85.0)\end{array}$ & $4462(76.7)$ & $\begin{array}{l}5825 \\
(78.5)\end{array}$ & $12(0.2)$ \\
\hline Chew ability, Good (\%) & $646(40.3)$ & $1609(27.7)$ & $\begin{array}{l}2255 \\
(30.4)\end{array}$ & $31(0.4)$ \\
\hline $\begin{array}{l}\text { Duration of cigarette smoking (years), mean } \\
\text { (SD) }\end{array}$ & $\begin{array}{l}54.7 \\
(16.9)\end{array}$ & $56.8(20.7)$ & $\begin{array}{l}56.3 \\
(19.9)\end{array}$ & $\begin{array}{l}498 \\
(6.7)\end{array}$ \\
\hline $\begin{array}{l}\text { Duration of alcohol drinking (years), mean } \\
\text { (SD) }\end{array}$ & $\begin{array}{l}49.9 \\
(19.9)\end{array}$ & $55.3(23.9)$ & $\begin{array}{l}54.1 \\
(23.2)\end{array}$ & $\begin{array}{l}537 \\
(7.2)\end{array}$ \\
\hline ADL score (points), mean (SD) & $0.2(0.8)$ & $0.8(1.4)$ & $0.7(1.3)$ & $60(0.8)$ \\
\hline IADL score (points), mean (SD) & $2.8(2.7)$ & $5.0(2.7)$ & $4.5(2.9)$ & $9(0.1)$ \\
\hline History of diabetes, Yes (\%) & $43(2.7)$ & $114(2.0)$ & $157(2.1)$ & $\begin{array}{l}395 \\
(5.3)\end{array}$ \\
\hline
\end{tabular}

Note. MMSE: Mini-mental state examination; ADL: Activities of daily living; IADL: Instrumental activities of daily living; BEPA: bronchitis, emphysema, asthma, pneumonia; TB: pulmonary tuberculosis. 


\begin{tabular}{|c|c|c|c|c|}
\hline Variables & $\begin{array}{l}\text { Reversion } \\
(n=1604)\end{array}$ & $\begin{array}{l}\text { Non- } \\
\text { reversion } \\
(n=5818)\end{array}$ & $\begin{array}{l}\text { Total } \\
(\mathrm{n}=7422)\end{array}$ & $\begin{array}{l}\text { Missing } \\
\text { (\%) }\end{array}$ \\
\hline History of heart disease, Yes (\%) & $128(8.0)$ & $409(7.0)$ & $537(7.2)$ & $\begin{array}{l}373 \\
(5.0)\end{array}$ \\
\hline History of cerebrovascular disease, Yes (\%) & $69(4.3)$ & $313(5.4)$ & $382(5.1)$ & $\begin{array}{l}363 \\
(4.9)\end{array}$ \\
\hline History of BEPA Yes (\%) & $140(8.7)$ & $542(9.3)$ & $682(9.2)$ & $\begin{array}{l}342 \\
(4.6)\end{array}$ \\
\hline History of TB, Yes (\%) & $8(0.5)$ & $26(0.4)$ & $34(0.5)$ & $\begin{array}{l}378 \\
(5.1)\end{array}$ \\
\hline \multicolumn{5}{|l|}{ Potential Modifiable Factors } \\
\hline Loneliness. Lonely (\%) & $143(8.9)$ & $562(9.7)$ & $705(9.5)$ & $\begin{array}{l}140 \\
(1.9)\end{array}$ \\
\hline Life satisfaction, Satisfied (\%) & $\begin{array}{l}1455 \\
(90.7)\end{array}$ & $5353(92.0)$ & $\begin{array}{l}6808 \\
(91.7)\end{array}$ & $25(0.3)$ \\
\hline \multicolumn{5}{|l|}{ Staple food (\%) } \\
\hline Rice & $\begin{array}{l}1001 \\
(62.4)\end{array}$ & $3553(61.1)$ & $\begin{array}{l}4554 \\
(61.4)\end{array}$ & \\
\hline Wheat & $351(21.9)$ & $1183(20.3)$ & $\begin{array}{l}1534 \\
(20.7)\end{array}$ & \multirow[t]{3}{*}{-} \\
\hline Corn & $48(3.0)$ & $198(3.4)$ & $246(3.3)$ & \\
\hline Others & $204(12.7)$ & $883(15.2)$ & $\begin{array}{l}1087 \\
(14.6)\end{array}$ & \\
\hline Intake of staple food (50 grams), mean (SD) & $6.1(2.8)$ & $5.4(2.5)$ & $5.58(2.6)$ & $\begin{array}{l}249 \\
(3.4)\end{array}$ \\
\hline Intake of fresh fruit, Daily (\%) & $463(28.9)$ & $1700(29.2)$ & $\begin{array}{l}2163 \\
(29.1)\end{array}$ & $3(0.0)$ \\
\hline Intake of fresh vegetable, Daily (\%) & $\begin{array}{l}1361 \\
(84.9)\end{array}$ & $4885(84.0)$ & $\begin{array}{l}6246 \\
(84.1)\end{array}$ & $5(0.1)$ \\
\hline Intake of meat, Daily (\%) & $431(26.9)$ & $1900(32.7)$ & $\begin{array}{l}2331 \\
(31.4)\end{array}$ & $8(0.1)$ \\
\hline Intake of fish, Daily (\%) & $171(10.7)$ & $701(12.0)$ & $872(11.7)$ & $7(0.1)$ \\
\hline Intake of egg, Daily (\%) & $525(32.7)$ & $2182(37.5)$ & $\begin{array}{l}2707 \\
(36.5)\end{array}$ & $8(0.1)$ \\
\hline $\begin{array}{l}\text { Note. MMSE: Mini-mental state examination; } \\
\text { activities of daily living; BEPA: bronchitis, em, } \\
\text { tuberculosis. }\end{array}$ & $\begin{array}{l}\text { ctivities } \\
\text { la, asth }\end{array}$ & $\begin{array}{l}\text { ly living; } \\
\text { eumonia }\end{array}$ & $\begin{array}{l}\text { Instrume } \\
\text { pulmona }\end{array}$ & \\
\hline
\end{tabular}




\begin{tabular}{|c|c|c|c|c|}
\hline Variables & $\begin{array}{l}\text { Reversion } \\
(n=1604)\end{array}$ & $\begin{array}{l}\text { Non- } \\
\text { reversion } \\
(n=5818)\end{array}$ & $\begin{array}{l}\text { Total } \\
(\mathrm{n}=7422)\end{array}$ & $\begin{array}{l}\text { Missing } \\
\text { (\%) }\end{array}$ \\
\hline Intake of legume (\%) & $394(24.6)$ & $1619(27.8)$ & $\begin{array}{l}2013 \\
(27.1)\end{array}$ & $11(0.1)$ \\
\hline Intake of salt-preserved vegetable, Daily (\%) & $390(24.3)$ & $1237(21.3)$ & $\begin{array}{l}1627 \\
(21.9)\end{array}$ & $12(0.2)$ \\
\hline Intake of sugar, Daily (\%) & $294(18.3)$ & $1379(23.7)$ & $\begin{array}{l}1673 \\
(22.5)\end{array}$ & $10(0.1)$ \\
\hline Intake of tea, Daily (\%) & $450(28.1)$ & $1350(23.2)$ & $\begin{array}{l}1800 \\
(24.3)\end{array}$ & $11(0.1)$ \\
\hline Intake of garlic, Daily (\%) & $293(18.3)$ & $991(17.0)$ & $\begin{array}{l}1284 \\
(17.3)\end{array}$ & $11(0.1)$ \\
\hline Current alcohol drinker (\%) & $313(19.5)$ & $\begin{array}{l}787 \\
(13.5 \%)\end{array}$ & $\begin{array}{l}1100 \\
(14.8)\end{array}$ & $18(0.2)$ \\
\hline Alcohol drinking (50 grams), mean (SD) & $2.8(2.8)$ & $2.4(2.4)$ & $2.5(2.5)$ & $\begin{array}{l}478 \\
(6.4)\end{array}$ \\
\hline Current smoker (\%) & $306(19.1)$ & $934(16.1)$ & $\begin{array}{l}1240 \\
(16.7)\end{array}$ & $15(0.2)$ \\
\hline Cigarette smoking (times/day), mean (SD) & $9.6(7.4)$ & $9.1(8.0)$ & $9.3(7.8)$ & $\begin{array}{l}434 \\
(5.8)\end{array}$ \\
\hline Doing exercise (\%) & $454(28.3)$ & $1248(21.5)$ & $\begin{array}{l}1702 \\
(22.9)\end{array}$ & $26(0.4)$ \\
\hline Doing housework, Almost daily (\%) & $995(62.0)$ & $1952(33.6)$ & $\begin{array}{l}2947 \\
(39.7)\end{array}$ & $5(0.1)$ \\
\hline $\begin{array}{l}\text { Having Personal outdoor activities, Almost } \\
\text { daily (\%) }\end{array}$ & $920(57.4)$ & $2524(43.4)$ & $\begin{array}{l}3444 \\
(46.4)\end{array}$ & $2(0.0)$ \\
\hline Doing garden work, Almost daily (\%) & $150(9.4)$ & $301(5.2)$ & $451(6.1)$ & $4(0.1)$ \\
\hline Reading books / newspaper, Almost daily (\%) & $113(7.0)$ & $270(4.6)$ & $383(5.2)$ & $4(0.1)$ \\
\hline Raising domestic animals, Almost daily (\%) & $439(27.4)$ & $840(14.4)$ & $\begin{array}{l}1279 \\
(17.2)\end{array}$ & $4(0.1)$ \\
\hline Playing cards / mah-jong, Almost daily (\%) & $141(8.8)$ & $247(4.2)$ & $388(5.2)$ & $4(0.1)$ \\
\hline $\begin{array}{l}\text { Watching TV / listening to the radio, Almost } \\
\text { daily (\%) }\end{array}$ & $933(58.2)$ & $2523(43.4)$ & $\begin{array}{l}3456 \\
(46.6)\end{array}$ & $2(0.0)$ \\
\hline Joining social activities, Almost daily (\%) & $54(3.4)$ & $111(1.9)$ & $165(2.2)$ & $5(0.1)$ \\
\hline
\end{tabular}




\begin{tabular}{|c|c|c|c|c|}
\hline Variables & $\begin{array}{l}\text { Reversion } \\
(n=1604)\end{array}$ & $\begin{array}{l}\text { Non- } \\
\text { reversion } \\
(n=5818)\end{array}$ & $\begin{array}{l}\text { Total } \\
(\mathrm{n}=7422)\end{array}$ & $\begin{array}{l}\text { Missing } \\
(\%)\end{array}$ \\
\hline Systolic blood pressure (Hg mm), mean (SD) & $\begin{array}{l}137.2 \\
(20.8)\end{array}$ & $\begin{array}{l}134.8 \\
(20.1)\end{array}$ & $\begin{array}{l}135.3 \\
(20.3)\end{array}$ & $\begin{array}{l}124 \\
(1.7)\end{array}$ \\
\hline Diatolic blood pressure ( $\mathrm{Hg} \mathrm{mm})$, mean (SD) & $\begin{array}{l}81.9 \\
(12.0)\end{array}$ & $82.0(12.7)$ & $\begin{array}{l}82.0 \\
(12.6)\end{array}$ & $\begin{array}{l}132 \\
(1.8)\end{array}$ \\
\hline Heart rate (beats/min), mean (SD) & $73.7(9.1)$ & $73.6(9.4)$ & $73.6(9.3)$ & $\begin{array}{l}130 \\
(1.8)\end{array}$ \\
\hline BMI $\left(\mathrm{kg} / \mathrm{m}^{2}\right)$, mean (SD) & $19.6(3.2)$ & $18.7(3.2)$ & $18.9(3.3)$ & $\begin{array}{l}311 \\
(4.2)\end{array}$ \\
\hline \multicolumn{5}{|c|}{$\begin{array}{l}\text { Note. MMSE: Mini-mental state examination; ADL: Activities of daily living; IADL: Instrumental } \\
\text { activities of daily living; BEPA: bronchitis, emphysema, asthma, pneumonia; TB: pulmonary } \\
\text { tuberculosis. }\end{array}$} \\
\hline
\end{tabular}

Eventually, 30 variables were selected by multivariable Cox regression with elastic net penalty. Age, gender, ethnic group, education, current marital status, visionary function, chew ability, duration of alcohol drinking, heart disease, cerebrovascular disease, BEPA, TB, MMSE, ADL and IADL score were selected as the institutional factors (covariates). A detailed information about their hazard ratios (HR) on reversion from $\mathrm{MCl}$ to $\mathrm{CN}$ can be found in Figure 1s.

Figure 2 displays the HRs of selected modifiable variables from multivariate Cox regression model. Compared with those who sometimes or never had fresh fruits, participants with daily fresh fruit intake were associated with increasing rate of $\mathrm{MCl}$ reversion (HR: 1.28, 95\% Cl: 1.15-1.42). Those who had daily meat intake were less likely to reverse (HR: $0.90,95 \% \mathrm{Cl}: 0.80-0.99)$ than those who sometimes or never consume meat. Apart from the above dietary factors, the type of staple food (rice, wheat, corn vs others) and its intake in 50 grams, daily intake of fresh vegetable, egg, salty-preserved vegetable and tea were also selected by the model, but no significant associations were found. Cigarette smoking (HR: 0.92, 95\% Cl: 0.84 to $1.00 ; \mathrm{P}=.041)$ and duration of alcohol drinking (HR: $0.97,95 \% \mathrm{Cl}: 0.94$ to $0.99 ; \mathrm{P}=.012$ ) were negatively associated with reversion. Doing housework daily (HR: $1.21,95 \% \mathrm{Cl}: 1.08-1.35)$, reading books or newspaper daily (HR: $1.24,95 \% \mathrm{Cl}: 1.00-1.54)$ and playing cards or mah-jong daily (HR:1.23, 95\% Cl: 1.08-1.39) were associated with higher possibility of reversion than those who did occasionally or never. Raising domestic animals and watching TV/ listening to radio daily were selected by the model but were not significantly associated with reversion of $\mathrm{MCl}$. According to the results of Schoenfeld residual test in Tables 1s, the proportional-hazards assumptions of each variable were not violated in this study.

The stepwise Cox regression model selected 16 variables in the final model (Table $2 \mathrm{~s}$ in Appendix). Of the 8 selected modifiable factors, intake of fresh fruit, intake of meat, doing housework, and playing cards/mah-jong were significantly associated with $\mathrm{MCl}$ reversion. No significant association was found between reading books/newspaper and $\mathrm{MCl}$ reversion in this model. By applying an additional restriction 
of MMSE change ( $\geq 2 \& \geq 3$ ) points) to our definition of reversion, we generated two slightly different models (figure $2 \mathrm{~s} \&$ figure $3 \mathrm{~s}$ ). In these models, daily intake of fresh fruit, daily doing housework daily and daily playing mah-jong or other card games were consistently found to be significantly associated with reversion. By using the listwise deletion to deal with missing value, the associations of daily intake of fresh fruit, doing housework daily and playing cards or mah-jong daily with reversion are also found to be significant (Figure 4s). Results from the modified Fine and Gray model that accounts for competing risks of mortality also demonstrated similar results (Figure $5 \mathrm{~s}$ ).

The sub-group analysis by age group (Table 3s in Appendix) indicated that daily intake of fresh fruit and daily doing housework might only be beneficial for $\mathrm{MCl}$ patients between 65 and 89 years old. For those who were 100 years old and above, daily watching TV/listening to the radio was positively associated with $\mathrm{MCl}$ reversion. In the sub-group analysis by gender (Table 4s in Appendix), daily fruit intake was significantly associated with reversion among female, but not among male; doing housework was significantly associated with reversion among male, but not among female.

\section{Discussion}

Previous studies on $\mathrm{MCl}$ reversion mostly investigated the influence of non-modifiable factors (eg. gender, age, genetics) and life-long factors that can no longer be changed in later age (eg. baseline cognitive functioning, education, co-morbidity, etc.). This study identified several dietary/behavioral factors significantly associated with higher possibility of $\mathrm{MCl}$ reversion, including daily consumption of fresh fruits, daily engagement in reading, housework, and mah-jong or other card games. Cigarette smoking and duration of alcohol consumption were identified as risk factors impeding $\mathrm{MCl}$ reversion. These factors were extracted from people's daily life in the studied context, and can potentially be transferred into cost-effective preventive practices.

To increase practical implication of our research findings, we analyzed the specific effect of each single activity on cognitive improvement among population with different demographic characteristics. Three activities, housework, reading books or newspaper, and playing cards or mah-jong, were positively associated with $\mathrm{MCl}$ reversion, respectively. These findings provide evidence that cognitive stimulation not only protects cognitive functioning from declining (25-28), but may also help those who already develop $\mathrm{MCl}$ achieve reversion to $\mathrm{CN}$. It is noteworthy that, although doing housework was associated with $\mathrm{MCl}$ reversion, no significant association was found between outdoor activities and $\mathrm{MCl}$ reversion. This may indicate that productive activities contribute more to cognitive functions than physical activities among Chinese older adults (29). A previous national longitudinal study in China has found that interacting with friends, playing mah-jong or other games, infrequently providing help to others and doing sport were beneficial for cognitive functioning among normal middle-aged and older adults (30). Both studies identified the beneficial effect of cognitive games and social interactions, which can be easily transferred into community-based dementia prevention programs. 
In terms of dietary factors, frequent consumption of meat was found to be negatively associated $\mathrm{MCl}$ reversion, probably explained by high volume of saturated fats in meat (31). Previous research has found significant association between intake of saturated fats and incident Alzheimer's disease (32), and such findings also apply to $\mathrm{MCl}$ reversion. However, previous studies have identified a negative association between high habitual fruit intake and cognitive health $(33,34)$, while frequent fruit consumption was found to be positively associated with $\mathrm{MCl}$ reversion in our study. In contrast, no significant association was found between frequent vegetable intake and $\mathrm{MCl}$ reversion. Effect of a single food on cognitive health can be attenuated by existent dietary patterns (35). A plausible explanation for the difference between our findings and previous results may be that vegetable is widely popular in Chinese diet and extra consumption of it may not have additional benefits. The negative effect of fruit on cognitive health found in previous research is mostly caused by extra sugar intake, while excessive sugar consumption is not as prevalent in Chinese diet, attenuating the negative impact of fruit. The benefit of fruit consumption may be explained by abundant Vitamin $C$ intake, which was found to have protective effect on cognitive health (36). Future studies investigating healthy diet need to take into consideration the cultural differences of the research contexts. Cigarette smoking was identified as a risk factor negatively associated with $\mathrm{MCl}$ reversion, in consistence with previous research which found it to be a risk factor for dementia incidence (37). Previous studies investigating the effect of alcohol on cognitive health mostly focused on quantity of alcohol consumption and have yielded mixed results (38-40). This study found that duration of alcohol consumption was negatively associated with possibility of $\mathrm{MCl}$ reversion, providing a new direction for research on alcohol consumption and cognitive health.

The sub-group analysis investigated how the association between modifiable factors and $\mathrm{MCl}$ reversion varies across age and gender. In general, the identified factors have more significant impact on the younger groups (65-89) compared to the older group (90 and above). Particularly, daily fruit intake and daily housework were significantly associated with $\mathrm{MCl}$ reversion among people between 65 and 90, but not among those who were above 90 . In contrast, watching TV/listening to radio daily, as a passive activity, was only significantly associated with higher possibility of reversion among people above 100 years old. This difference may be explained by the impact of aging on neuroplasticity: younger people may more easily increase neuroplasticity and achieve cognitive improvement through lifestyle changes, while older people may have less opportunity to reverse and need to depend on external mental stimulation (41). In terms of gender difference, doing housework was significantly associated with higher possibility of reversion among male, but not among female. This difference might be caused by cultural norms that require women to routinely do housework, and therefore more frequent involvement does not provide extra stimulation.

Three large-scale RCTs, respectively FINGER (11), MAPT (12), and PreDIVA (13), were conducted to prevent dementia through lifestyle interventions, and only FINGER found positive effects. Which specific factors contributed to these effects, however, were not further studied. This study further analyzed the effect of each specific modifiable factor on cognitive reversion and identified several potential protective factors. Several other studies found some modifiable factors contributing to $\mathrm{MCl}$ reversion. A study of $396 \mathrm{MCl}$ participants in Japan found that driving a car, using a map to travel to unfamiliar places, reading 
books or newspapers, taking cultural classes, attending meetings in the community, participating in hobbies or sports activities and engaging in fieldwork or gardening are all beneficial to cognitive recovery (25). It is noteworthy that the results were only significant in the imputed data which augmented the original sample size from 396 to 37,893 by multiple imputation, rendering the conclusions questionable. Moreover, this study ignored nutritional, cardiometabolic and psychological factors, providing limited guidance on health habits. Two other studies of similar sample size and research design were conducted in Australia (26) and Korea (27). Both studies recommended engagement in social activities for people with $\mathrm{MCl}$, but activities were only measured by number and frequency, leaving the effect of specific activities unknown. Great cultural differences exist in the types of activities researched, and the measurement of activity participation also varies. Such difference compromises the generalizability of these findings in a different context.

This is by far the largest and most comprehensive cohort study on the modifiable factors associated with reversion from $\mathrm{MCl}$ to $\mathrm{CN}$. We only included factors that were still modifiable when patients had already suffered from $\mathrm{MCl}$. Therefore, findings of this study can be transferred to practice of secondary prevention of dementia. Moreover, variable selection method was widely used to generate data-driven research hypothesis (42). This study integrated both theory-driven and data-driven methods to generate research hypotheses. We first came up with many research hypotheses by comprehensively reviewing previous study on dementia. Then we used a new variable selection method, LASSO instead of traditional stepwise (back-n-forth) method to avoid multicollinearity in the final model. In sensitivity analysis, we found stepwise (back-n-forth) method failed to detect one significant modifiable factor because it usually provides less stable results than LASSO. The large sample size of this study also allowed us to draw robust conclusions among young old, octogenarians, nonagenarians, and centenarians, providing detailed information of dementia prevention for each age group.

\section{Limitations}

This study has several limitations. First, the sample and the modifiable factors were mostly from the context in China, rendering the results less generalizable across the world. Also, the participants in this study are comparatively old (mean age $=90.0$ years). It did not affect the internal validity of this study, but generalization of reversion rates to the entire older population should be cautious. Second, in this study, $\mathrm{MCl}$ was measured by MMSE, and its sensitivity in screening $\mathrm{MCl}$ is lower than Montreal Cognitive Assessment (MOCA). However, MMSE still has a comparable performance on detection of $\mathrm{MCl}$ with 0.62 sensitivity and 0.87 specificity in Chinese population (43). Thirdly, most of the clinical diseases adjusted as confounding factors were self-reported; participants were asked whether diseases had been diagnosed by a doctor. The study identified several modifiable factors that may help $\mathrm{MCl}$ patients recover, but those who reverted may have higher risk for future cognitive decline (10). Further studies should explore modifiable factors that may keep the older adults remain at $\mathrm{CN}$ status. Carrying apolipoprotein E (APOE) may attenuate or even offset the potential positive effects of the modifiable factors (44), but the current study could not test the attenuation effect of genetics for lack of genetic information. Fourth, our study could not cover all modifiable factors, although we assessed all available modifiable factors collected in 
CLHLS. Last, due to the possibility of reverse causality, the results should also be interpreted with caution. Participants who were able to conduct healthy activities may have less severe symptoms and therefore, higher chance of reversion.

\section{Conclusion}

The current study identified several modifiable factors among the Chinese MCl population, potentially leading to cost-effective nation-wide interventions. Facilitating people suffering from $\mathrm{MCl}$ to build a cognition-friendly lifestyle can be a new strategy for dementia prevention. Randomized controlled trials are needed in the future to determine the effectiveness of these lifestyle interventions.

\section{Abbreviations}

ADL: activities of daily living

APOE: apolipoprotein E

BEPA: bronchitis, emphysema, asthma, and pneumonia

BMI: body mass index

Cl: confidence interval

CLHLS: Chinese Longitudinal Healthy Longevity Survey

$\mathrm{CN}$ : cognitively normal

FFQ: food frequency questionnaire

HR: Hazard Ratio

IADL: instrumental activities of daily living

LASSO: Least absolute shrinkage and selection operator

MCl: mild cognitive impairment

MMSE: Mini-mental State Examination

MOCA: Montreal Cognitive Assessment

SD: standard deviation

TB: pulmonary tuberculosis 


\section{Declarations}

\section{Ethics approval and consent to participate:}

The Chinese Longitudinal Healthy Longevity Survey (CLHLS) was approved by the Institutional Review Board, Duke University (Pro00062871), and the Biomedical Ethics Committee, Peking University (IRB00001052-13074). Permissions are required to access the raw data from the CLHLS. This study obtained the CLHLS data by submitting a data use agreement, which was approved by Zheng Zhenzhen, Executive Associate Director of Center for Healthy Aging and Family Studies, Peking University.

\section{Consent for publication:}

\section{Not applicable.}

\section{Availability of data and materials}

The analytical dataset used in this study is a publicly available dataset released by the CLHLS. Information about the data source and available data are found at https://opendata.pku.edu.cn/dataset.xhtml?persistentld=doi:10.18170/DVN/XRV2WN. Researchers can obtain these data after submitting a data use agreement to the CLHLS team.

\section{Competing interests}

The authors declare that they have no conflict of interest.

Funding: This work was supported by the Strategic Priority CAS Project (Grant No.XDB38040200), Guangdong Philosophy and Social Science Fund (GD21YSH06), Shenzhen Philosophy and Social Science Fund (Grant No. SZ2020C015), Shenzhen Science and Technology Fund (Grant No. 20200805164059001), and the Shenzhen Science and Technology Program (Grant No. KQTD20190929172835662هJCYJ20180703145002040). The funding body had no role in the design of the study and collection, analysis, and interpretation of data and in writing the manuscript.

\section{Author's contribution}

Dr. Bingyu Li and Dr. Feng Sha are responsible for the research design, methodology development, discussion and manuscript writing. Mr. Ziyi Zhao contributed greatly to the data cleaning, data analysis and discussion. Dr. Zhirong Yang and Ms. Chang Wei provided important comments and suggestions.

\section{Acknowledgements}

Data used in this analysis were provided by the CLHLS study, which was coordinated by the Center for Healthy Ageing and Development Studies, Peking University. The authors would like to thank CLHLS participants and researchers for their contributions to this important study. 


\section{References}

1. Kissimova-Skarbek K. Global, regional, and national burden of Alzheimer's disease and other dementias, 1990-2016: a systematic analysis for the Global Burden of Disease Study 2016. Lancet Neurol. 2019;18(1). doi:10.1016/S1474-4422(18)30403-4.

2. Wood $\mathrm{H}$. Meta-analysis finds high reversion rate from $\mathrm{MCl}$ to normal cognition. Nature Reviews Neurology. 2016;12(4):189-9. doi:https://doi.org/10.1038/nrneurol.2016.29.

3. Malek-Ahmadi M. Reversion from mild cognitive impairment to normal cognition. Alzheimer Disease Associated Disorders. 2016;30(4):324-30. doi:https://doi.org/10.1097/WAD.0000000000000145.

4. Livingston G, Huntley J, Sommerlad A, et al. Dementia prevention, intervention, and care: 2020 report of the Lancet Commission. The Lancet. 2020. doi:10.1016/S0140-6736(20)30367-6.

5. Sommer I, Griebler U, Kien C, et al. Vitamin D deficiency as a risk factor for dementia: a systematic review and meta-analysis. BMC Geriatr. 2017;17(1):16. doi:10.1186/s12877-016-0405-0.

6. Chan JY, Yiu KK, Kwok TC, Wong SY, Tsoi KK. Depression and antidepressants as potential risk factors in dementia: a systematic review and meta-analysis of 18 longitudinal studies. J Am Med Dir Assoc. 2019;20(3):279-86. doi:10.1016/j.jamda.2018.12.004. e1.

7. Penninkilampi R, Casey A-N, Singh MF, Brodaty H. The association between social engagement, Ioneliness, and risk of dementia: a systematic review and meta-analysis. J Alzheimers Dis. 2018;66(4):1619-33. doi:10.3233/JAD-180439.

8. Xue H, Hou P, Li Y, Mao Xe, Wu L, Liu Y. Factors for predicting reversion from mild cognitive impairment to normal cognition: A meta-analysis. Int J Geriatr Psychiatry. 2019;34(10):1361-8. doi:10.1002/gps.5159.

9. Roberts RO, Knopman DS, Mielke MM, et al. Higher risk of progression to dementia in mild cognitive impairment cases who revert to normal. Neurology. 2014;82(4):317-25.

doi:10.1212/WNL.0000000000000055.

10. Koepsell TD, Monsell SE. Reversion from mild cognitive impairment to normal or near-normal cognition: risk factors and prognosis. Neurology. 2012;79(15):1591-8. doi:https://doi.org/10.1212/WNL.0b013e31826e26b7.

11. Ngandu T, Lehtisalo J, Solomon A, et al. A 2 year multidomain intervention of diet, exercise, cognitive training, and vascular risk monitoring versus control to prevent cognitive decline in at-risk elderly people (FINGER): a randomised controlled trial. The Lancet. 2015;385(9984):2255-63. doi:10.1016/S0140-6736(15)60461-5.

12. Andrieu S, Guyonnet S, Coley N, et al. Effect of long-term omega 3 polyunsaturated fatty acid supplementation with or without multidomain intervention on cognitive function in elderly adults with memory complaints (MAPT): a randomised, placebo-controlled trial. Lancet Neurol. 2017;16(5):377-89. doi:10.1016/S1474-4422(17)30040-6.

13. van Charante EPM, Richard E, Eurelings LS, et al. Effectiveness of a 6-year multidomain vascular care intervention to prevent dementia (preDIVA): a cluster-randomised controlled trial. The Lancet. 
2016;388(10046):797-805. doi:10.1016/S0140-6736(16)30950-3.

14. Kivipelto M, Mangialasche F, Ngandu T. Lifestyle interventions to prevent cognitive impairment, dementia and Alzheimer disease. Nature Reviews Neurology. 2018;14(11):653-66. doi:10.1038/s41582-018-0070-3.

15. Zeng Y, Feng Q, Hesketh T, Christensen K, Vaupel JW. Survival, disabilities in activities of daily living, and physical and cognitive functioning among the oldest-old in China: a cohort study. Lancet Apr. 2017;22(10079):1619-29. doi:10.1016/s0140-6736(17)30548-2. 389 ) .

16. Cui GH, Yao YH, Xu RF, et al. Cognitive impairment using education-based cutoff points for CMMSE scores in elderly Chinese people of agricultural and rural Shanghai China. Acta Neurol Scand Dec. 2011;124(6):361-7. doi:10.1111/j.1600-0404.2010.01484.x.

17. Pezzotti P, Scalmana S, Mastromattei A, Di Lallo D. The accuracy of the MMSE in detecting cognitive impairment when administered by general practitioners: a prospective observational study. BMC Fam Pract May. 2008;13:9:29. doi:10.1186/1471-2296-9-29.

18. Yuan J-Q, Lv Y-B, Chen H-S, et al. Association Between Late-Life Blood Pressure and the Incidence of Cognitive Impairment: A Community-Based Prospective Cohort Study. J Am Med Dir Assoc. 2019/02/01/ 2019;20(2):177-82.e2. doi:https://doi.org/10.1016/j.jamda.2018.05.029.

19. An R, Liu GG. Cognitive impairment and mortality among the oldest-old Chinese. Int J Geriatr Psychiatry Dec. 2016;31(12):1345-53. doi:10.1002/gps.4442.

20. Hensel A, Angermeyer MC, Riedel-Heller SG. Measuring cognitive change in older adults: reliable change indices for the Mini-Mental State Examination. J Neurol Neurosurg Psychiatry Dec. 2007;78(12):1298-303. doi:10.1136/jnnp.2006.109074.

21. Zhang $\mathrm{H}$, Hsu-Hage $\mathrm{BH}$, Wahlqvist ML. The use of knee height to estimate maximum stature in elderly Chinese. J Nutr Health Aging. 1998;2(2):84-7. doi: unavailable.

22. Simon N, Friedman J, Hastie T, Tibshirani R. Regularization Paths for Cox's Proportional Hazards Model via Coordinate Descent. J Stat Softw Mar. 2011;39(5):1-13. doi:10.18637/jss.v039.i05.

23. Tibshirani R. The lasso method for variable selection in the Cox model. Stat Med. Feb 28 1997;16(4):385-95. doi:10.1002/(sici)1097-0258(19970228)16:4<385::aid-sim380>3.0.co;2-3

24. Shah AD, Bartlett JW, Carpenter J, Nicholas O, Hemingway H. Comparison of Random Forest and Parametric Imputation Models for Imputing Missing Data Using MICE: A CALIBER Study. Am J Epidemiol. 2014;179(6):764-74. doi:10.1093/aje/kwt312.

25. Wang J, Zhou D, Li J, et al. Leisure activity and risk of cognitive impairment: the Chongqing aging study. Neurology. 2006;66(6):911-3. doi:10.1212/01.wnl.0000192165.99963.2a.

26. Verghese J, Lipton RB, Katz MJ, et al. Leisure activities and the risk of dementia in the elderly. $\mathrm{N}$ Engl J Med. 2003;348(25):2508-16. doi:10.1056/NEJMoa022252.

27. Sturman MT, Morris MC, Mendes de Leon CF, Bienias JL, Wilson RS, Evans DA. Physical Activity, Cognitive Activity, and Cognitive Decline in a Biracial Community Population. Arch Neurol. 2005;62(11):1750-4. doi:10.1001/archneur.62.11.1750. 
28. Lee AT, Richards M, Chan WC, Chiu HF, Lee RS, Lam LC. Association of daily intellectual activities with lower risk of incident dementia among older Chinese adults. JAMA psychiatry. 2018;75(7):697703. doi:10.1001/jamapsychiatry.2018.0657.

29. Luo Y, Pan X, Zhang Z. Productive activities and cognitive decline among older adults in China: Evidence from the China Health and Retirement Longitudinal Study. Soc Sci Med. 2019/05/01/ 2019;229:96-105. doi:https://doi.org/10.1016/j.socscimed.2018.09.052.

30. Li B, Bi J, Wei C, Sha F. Specific Activities and the Trajectories of Cognitive Decline Among MiddleAged and Older Adults: A Five-Year Longitudinal Cohort Study. J Alzheimers Dis Feb 20 2021;doi:10.3233/jad-201268.

31. Barnard ND, Bush Al, Ceccarelli A, et al. Dietary and lifestyle guidelines for the prevention of Alzheimer's disease. Neurobiol Aging. 2014;35:74-8. doi:10.1016/j.neurobiolaging.2014.03.033.

32. Barnard ND, Bunner AE, Agarwal U. Saturated and trans fats and dementia: a systematic review. Neurobiol Aging. 2014;35:65-73. doi:10.1016/j.neurobiolaging.2014.02.030.

33. Davin A, Ceretti A, Mimmi MC, Cereda C, Guaita A. Habitual consumption of fruit, folic acid and cobalamin as risk/protection factors for the incidence of dementia: Data from the 'InveCe.Ab' study. Alzheimer's Dement. 2020;16(S10):e043654. doi:https://doi.org/10.1002/alz.043654.

34. Kang JH, Ascherio A, Grodstein F. Fruit and vegetable consumption and cognitive decline in aging women. Ann Neurol. 2005;57(5):713-20. doi:https://doi.org/10.1002/ana.20476.

35. Agarwal P, Dhana K, Barnes LL, et al. Unhealthy foods may attenuate the beneficial relation of a Mediterranean diet to cognitive decline. Alzheimer's \& Dementia. doi: 10.1002/alz.12277.

36. Scarmeas N, Anastasiou CA, Yannakoulia M. Nutrition and prevention of cognitive impairment. Lancet Neurol. 2018;17(11):1006-15. doi:10.1016/S1474-4422(18)30338-7.

37. Hernán MA, Alonso A, Logroscino G. Commentary. Cigarette smoking and dementia: Potential selection bias in the elderly. Epidemiology. 2008:448-450.

38. Wiegmann C, Mick I, Brandl EJ, Heinz A, Gutwinski S. Alcohol and Dementia-What is the Link? A Systematic Review. Neuropsychiatr Dis Treat. 2020;16:87.

39. Purnell C, Gao S, Callahan CM, Hendrie HC. Cardiovascular risk factors and incident Alzheimer disease: a systematic review of the literature. Alzheimer Dis Assoc Disord. 2009;23(1):1.

40. Piazza-Gardner AK, Gaffud TJ, Barry AE. The impact of alcohol on Alzheimer's disease: a systematic review. Aging Ment Health. 2013;17(2):133-46.

41. Jones S, Nyberg L, Sandblom J, et al. Cognitive and neural plasticity in aging: general and taskspecific limitations. Neuroscience Biobehavioral Reviews. 2006;30(6):864-71. doi:10.1016/j.neubiorev.2006.06.012.

42. Pandya SY, Lacritz LH, Weiner MF, Deschner M, Woon FL. Predictors of reversion from mild cognitive impairment to normal cognition. Dement Geriatr Cogn Disord. 2017;43(3-4):204-14. doi:10.1159/000456070. 
43. Tsoi KKF, Chan JYC, Hirai HW, Wong SYS, Kwok TCY. Cognitive Tests to Detect Dementia: A Systematic Review and Meta-analysis. JAMA Internal Medicine. 2015;175(9):1450-8. doi:10.1001/jamainternmed.2015.2152.

44. Licher S, Ahmad S, Karamujić-Čomić $\mathrm{H}$, et al. Genetic predisposition, modifiable-risk-factor profile and long-term dementia risk in the general population. Nature medicine. 2019;25(9):1364-9. doi:10.1038/s41591-019-0547-7.

\section{Figures}

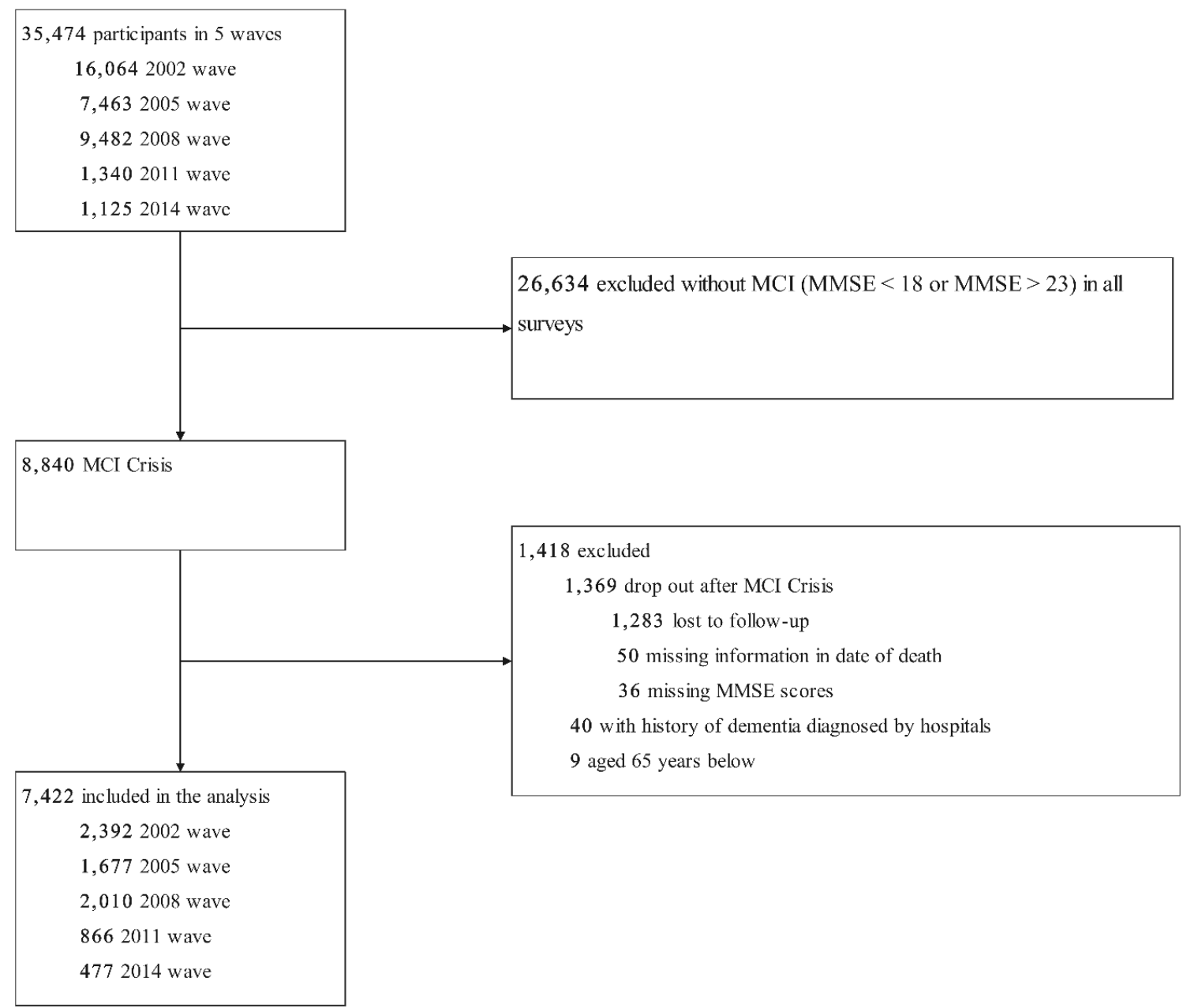

\section{Figure 1}

Flowchart of data cleaning 


\begin{tabular}{|c|c|c|c|c|}
\hline Variable & Scaling of HR & & $\mathrm{HR}(95 \% \mathrm{Cl})$ & $\mathrm{p}$-value \\
\hline Staple food,corn & & $\longmapsto \longrightarrow$ & $0.96(0.74,1.26)$ & 0.781 \\
\hline Staple food, wheat & & $\longmapsto \longrightarrow$ & $1.07(0.84,1.36)$ & 0.583 \\
\hline Staple food,others & & $\longmapsto \longrightarrow$ & $0.93(0.76,1.15)$ & 0.522 \\
\hline Intake of staple food & 1 liang higher log-hazard & 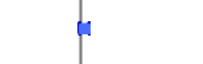 & $1.02(0.99,1.04)$ & 0.101 \\
\hline Fresh fruit, daily & & $\mapsto$ & $1.28(1.15,1.42)$ & $<0.001$ \\
\hline Fresh vegetable, daily & & $\mapsto-1$ & $0.90(0.75,1.08)$ & 0.256 \\
\hline Meat,daily & & $\mapsto-1$ & $0.90(0.80,0.99)$ & 0.047 \\
\hline Egg,daily & & $\mapsto-$ & $0.94(0.83,1.06)$ & 0.324 \\
\hline Salty-preserved vegetable, daily & & ト- & $0.95(0.82,1.10)$ & 0.470 \\
\hline Tea,daily & & $\mapsto-1$ & $1.08(0.96,1.22)$ & 0.211 \\
\hline Cigarette smoking & 10 times higher log-hazard & $r-1$ & $0.92(0.84,1.00)$ & 0.041 \\
\hline Duration of alcohol drinking & 10 years higher log-hazard & 同 & $0.97(0.94,0.99)$ & 0.012 \\
\hline Housework,almost daily & & $\mapsto$ & $1.21(1.08,1.35)$ & 0.001 \\
\hline Books/newspaper,almost daily & & -1 & $1.24(1.00,1.54)$ & 0.047 \\
\hline Domestic animals,almost daily & & $\mapsto$ & $1.05(0.91,1.20)$ & 0.500 \\
\hline Cards/mah-jong,almost daily & & $\mapsto \longrightarrow$ & $1.23(1.08,1.39)$ & 0.001 \\
\hline TV/radio:almost daily & & $\mapsto$ & $1.10(0.95,1.27)$ & 0.223 \\
\hline Systolic blood pressure & $1 \mathrm{SD}$ higher log-hazard & $p=-1$ & $1.05(0.99,1.12)$ & 0.120 \\
\hline Heart rate & $1 \mathrm{SD}$ higher log-hazard & $t-1$ & $1.04(0.98,1.10)$ & 0.231 \\
\hline
\end{tabular}

\section{Figure 2}

The hazard ratio $(95 \% \mathrm{Cl})$ and $\mathrm{p}$-values for selected modifiable variables from Cox regression with LASSO method (MMSE change $\geq 4$ as additional restriction).

\section{Supplementary Files}

This is a list of supplementary files associated with this preprint. Click to download.

- Appendix1014.docx 